\title{
Over de (on)mogelijkheid van de ontbindende voorwaarde onder de Wwz
}

\author{
mr. Marian van Eck*
}

\section{Inleiding}

De Wet werk en zekerheid (Wwz) heeft geen verandering gebracht in de gelaagde structuur van het Burgerlijk Wetboek (BW). Dat betekent dat de algemene regels uit Boek 3 en Boek $6 \mathrm{BW}$ in beginsel van toepassing zijn, zoals blijkt uit de zogenoemde schakelbepalingen van artikel 3:59 en 6:216 BW. Het beginsel van cumulatie geldt en de rechtzoekende kan zo nodig de voor hem gunstigste regel kiezen (alternativiteit), tenzij bepaalde regels exclusieve werking hebben. Dat moet blijken uit de wettekst, de strekking van de regel of de bedoeling van de wetgever. De artikelen 3:59 en 6:216 BW bepalen meer specifiek dat de regels uit Boek 3 en Boek 6 BW van overeenkomstige toepassing zijn voor zover de aard van de rechtshandeling of de rechtsbetrekking zich daartegen niet verzet.

De basis voor de ontbindende voorwaarde ligt in artikel 3:38 BW en artikel 6:216 BW. Volgens artikel 3:38 BW kan een rechtshandeling onder een voorwaarde verricht worden, eveneens tenzij uit de wet of uit de aard van de rechtshandeling anders voortvloeit. Volgens artikel $6: 216 \mathrm{BW}$ is een verbintenis voorwaardelijk, wanneer bij rechtshandeling haar werking van een toekomstige onzekere gebeurtenis afhankelijk is gesteld. Als slechts het tijdstip waarop de voorwaarde intreedt onzeker is, is sprake van een verbintenis onder tijdsbepaling.

De kernvraag in dit artikel is of de ontbindende voorwaarde onder de Wwz nog mogelijk is. Van Slooten bepleit in zijn artikel van wel en geeft daarvoor twee redenen, waarover hierna meer. In dit artikel zal ik eerst kort de visie van de Hoge Raad vóór de Wwz samenvatten en de lagere rechtspraak sinds de Wwz. Vervolgens zal ik ingaan op de redenen die Van Slooten geeft voor handhaving van de ontbindende voorwaarde onder de $\mathrm{Wwz}$, mogelijke redenen tegen en afsluiten met een conclusie.

\section{De Hoge Raad vóór de Wwz}

Onder oud recht heeft de Hoge Raad zich vijf maal uitgelaten over de toelaatbaarheid van de ontbindende voorwaarde: Mungra (HR 6 maart 1992, Nf 1992/509), Van Zijl/Koppen (HR 24 mei 1996, N7 1996/685), Port de Plaisance (HR 13 februari 1998, Nf 1998/708), Monte/Bank (HR 1 februari 2002, $\mathcal{F} A R$ 2002/45) en HTM Personenvervoer (HR 2 november 2012, $7 A R$ 2012/314). Uit deze arresten kunnen de volgende conclusies worden getrokken.

Allereerst hechtte de Hoge Raad grote betekenis aan het toenmalige gesloten ontslagstelsel (welk stelsel de Hoge Raad in het laatste (HTM-)arrest overigens niet langer gesloten noemde maar 'wettelijk'). De ontbindende voorwaarde kon - vanwege dit ontslagstelsel - volgens de Hoge Raad slechts bij uitzondering worden anvaard. Van geval tot geval moest worden beoordeeld of en in hoeverre de strekking van de regels tot nietigheid van de ontbindende voorwaarde zou leiden. Deze aanpak strookte volgens de Hoge Raad met het bepaalde in artikel 7A:1639e lid 3 en 4 BW (oud), waarin slechts de geldigheid van de daar bedoelde ontbindende voorwaarden (te weten wegens huwelijk, zwangerschap of bevalling) werd uitgesloten. ${ }^{1}$ Uit de verschillende arresten werd ook duidelijk dat de toets in ieder geval tot nietigheid zou leiden als de voorwaarde niet objectief bepaalbaar was of als de inwerkingtreding door de werkgever beïnvloed kon worden (ook wel het triggerverbod genoemd). De voorwaarde mocht evenmin wettelijke opzegverboden omzeilen. Het feit dat de arbeidsovereenkomst inhoudsloos werd (zoals in het Mungra-arrest waar de betreffende arts door de ingetrokken vergunning zijn werk als arts niet meer mocht doen), bleek in het HTMarrest geen noodzakelijke voorwaarde (meer) voor het aannemen van een geldige ontbindende voorwaarde, maar slechts een mee te wegen omstandigheid. In het HTM-arrest maakte de Hoge Raad duidelijk dat de ontbindende voorwaarde redelijkerwijs met het (toenmalige) wettelijke ontslagstelsel verenigbaar diende te zijn, waarbij het mede ankwam op de aard, inhoud en context van de ontbindende voorwaarde. Ondanks dat de Hoge Raad bij herhaling oordeelde dat de ontbindende voorwaarde slechts bij uitzondering aanvaard kon wor- 
den, achtte hij drie van de vijf ontbindende voorwaarden geldig. ${ }^{2}$

\section{De ontbindende voorwaarde onder de Wwz}

In de parlementaire geschiedenis bij de Wwz is geen (expliciete) aandacht besteed aan de mogelijkheid van een ontbindende voorwaarde onder de Wwz. Dat betekent mijns inziens niet dat zonder meer geconcludeerd mag worden dat de mogelijkheden exact dezelfde zijn gebleven als voor de Wwz. De Wwz heeft immers een ingrijpende stelselwijziging tot stand gebracht en dat leidt tot allerhande - mijns inziens valide - vragen in dit kader.

Is een einde van rechtswege van de arbeidsovereenkomst voor onbepaalde tijd, waar de inwerkingtreding van de voorwaarde toe zal leiden, nog verenigbaar met dit nieuwe ontslagstelsel? Is het verenigbaar met de verplichte (proces)routes via UWV of kantonrechter? En past een ontbindende voorwaarde - materieel bezien - in het (limitatieve) grondenstelsel? Opzegging van de arbeidsovereenkomst is sinds de Wwz immers alleen nog toegestaan als de reden valt onder een van de gronden opgenomen in artikel 7:669 lid $3 \mathrm{BW}$. En hoe valt die ontbindende voorwaarde in te passen binnen de (sinds de Wwz explicietere) herplaatsingsverplichting van de werkgever? Ook al is een redelijke grond uit artikel 7:669 lid 3 BW aanwezig, dan moet vervolgens door de werkgever in beginsel nog aannemelijk worden gemaakt dat er geen redelijke herplaatsingsmogelijkheid is binnen de groep van ondernemingen waar de werkgever deel van uitmaakt. De Laat heeft betoogd dat de werknemer zich op deze Wwz-herplaatsingsverplichting mag beroepen in het kader van de toetsing van de geldigheid van de ontbindende voorwaarde. ${ }^{3}$ Maar strookt dat wel met het vermogensrecht? In mijn visie dient eerst de vraag gesteld te worden of de ontbindende voorwaarde nog past in het Wwz-stelsel en als het antwoord daarop bevestigend zou zijn, dan komt het volgens Boek 3 en Boek 6 BW mijns inziens uitsluitend neer op de vraag of de voorwaarde een toekomstige onzekere gebeurtenis

2. Geldige ontbindende voorwaarden werden door de Hoge Raad aangenomen in Mungra, Monte/Bank en HTM. In het Mungra-arrest leek het inhoudsloos worden van de arbeidsovereenkomst een belangrijke voorwaarde, alsook dat een derde - en niet de werkgever - de vergunning ingetrokken had. In Monte/Bank (waarin overigens het toenmalige BBA niet gold) ging het ook om een besluit van een ander dan de werkgever (de landsgouverneur), welk besluit tot stand was gekomen via een met waarborgen omklede procedure. In HTM leek het bijzondere karakter van de zogenoemde ID-subsidieregeling een belangrijke omstandigheid. De ontbindende voorwaarden in Van Zijl/Koppen en Port de Plaisance werden door de Hoge Raad nietig geacht, omdat in Van Zijl/Koppen het opzegverbod wegens overgang van onderneming werd omzeild en in Port de Plaisance omdat de werkgever kon beslissen wanneer en welke bedrijfsactiviteiten weer hervat zouden worden na de orkaanschade en de werkgever kon kiezen welke werknemers wel het werk zouden hervatten en welke niet (waarmee de selectiecriteria omzeild werden).

3. J.J.M. de Laat, 'De ontbindende voorwaarde in het nieuwe ontslagrecht', TRA 2014/100 betreft en of aan de hiervoor samengevatte voorwaarden uit de rechtspraak van de Hoge Raad wordt voldaan. Daar past een extra toets of de werkgever redelijkerwijs kan herplaatsen mijns inziens niet in. In de rechtspraak van de Hoge Raad onder oud recht zijn ook geen aanknopingspunten te vinden voor zo'n extra toets. Volgens de Hoge Raad in het HTM-arrest wordt gewicht toegekend aan de aard, inhoud en context van de ontbindende voormaarde zelf en niet aan omstandigheden die bij de werkgever spelen (zoals het hebben van herplaatsingsmogelijkheden) voor de beoordeling of de overeengekomen ontbindende voorwaarde geldig is. Hooguit zou een werknemer bij een geldig geachte ontbindende voorwaarde een beroep op artikel 6:248 lid 2 BW kunnen doen en stellen dat de werkgever naar maatstaven van redelijkheid en billijkheid geen beroep toekomt op de ontbindende voorwaarde als er (concrete) herplaatsingsmogelijkheden zijn. Ik acht dat beroep niet snel kansrijk. Een tussen partijen geldende regel is ingevolge artikel 6:248 lid 2 BW immers alleen niet van toepassing als dat in de gegeven omstandigheden naar maatstaven van redelijkheid en billijkheid onaanvaardbaar zou zijn. Hooguit in uitzonderlijke gevallen zou dat aan de orde kunnen zijn. De bescherming die de werknemer via de band van artikel 6:248 lid $2 \mathrm{BW}$ kan verkrijgen staat in ieder geval niet in verhouding tot de wettelijke herplaatsingsverplichting van de werkgever onder de Wwz.

Als de ontbindende voorwaarde nog steeds mogelijk wordt geacht onder de Wwz, mist de werknemer mijns inziens de mogelijkheid een beroep te doen op nakoming van de herplaatsingsverplichting die bij een 'regulier ontslag' wel gegolden had (tenzij herplaatsing niet mogelijk is of niet in de rede ligt). Of negatiever geformuleerd: als de ontbindende voorwaarde nog steeds mogelijk wordt geacht onder de $\mathrm{Wwz}$, kan de werkgever via een geldige ontbindende voorwaarde een herplaatsingsverplichting voorkomen die hij bij een 'regulier ontslag' (op dezelfde grond) wel had gehad.

Tot slot is interessant of er - als de ontbindende voorwaarde in werking treedt na twee jaar - recht bestaat op een transitievergoeding. Dat einde van rechtswege valt niet onder artikel 7:673 lid 1 onderdeel a onder $1^{\circ}$ (de werkgever heeft de arbeidsovereenkomst niet opgezegd; alleen de voorwaarde is in werking getreden) of onder $2^{\circ}$ (de arbeidsovereenkomst is ook niet ontbonden op verzoek van de werkgever). Artikel 7:673 lid 1 onderdeel a onder $3^{\circ} \mathrm{BW}$ ziet op de situatie dat 'na een einde van rechtswege op initiatief van de werkgever niet aansluitend is voortgezet en voor het eindigen van de arbeidsovereenkomst geen opvolgende arbeidsovereenkomst is aangegaan.' Allereerst heeft het einde van rechtswege bij een ontbindende voorwaarde en/of de niet-voortzetting niet op initiatief van merkgever ${ }^{4}$ plaatsgevonden. Het is nu juist de inwerkingtreding van de ontbindende voorwaarde geweest die het einde van de arbeidsovereen-

4. Als een ontbindende voorwaarde op initiatief van werkgever in werking zou treden, zou dat immers in strijd zijn met de rechtspraak van vóór de Wwz, namelijk dat de werkgever de inwerkingtreding van de voorwaarde niet mag (kunnen) beïnvloeden (triggerverbod) 
komst (en geen voortzetting van die arbeidsovereenkomst) heeft bewerkstelligd. Ten tweede zal de werkgever vóór het in werking treden van een ontbindende voorwaarde geen opvolgende arbeidsovereenkomst (kunnen) zijn aangegaan. De werkgever weet immers niet wanneer en of de ontbindende voorwaarde in werking treedt en mag dat ook niet (kunnen) beïnvloeden. De bepaling van artikel 7:673 lid 1 onderdeel a onder $3^{\circ}$ BW lijkt uitsluitend geschreven te zijn voor niet-voortzetting van een tijdelijke arbeidsovereenkomst na twee jaar. Dat wordt ook ondersteund door de parlementaire geschiedenis,${ }^{5}$ waarin expliciet wordt uitgelegd dat de transitievergoeding onder de Wwz niet alleen bij onbepaaldetijdcontracten verschuldigd is, maar ook bij tijdelijke contracten, mits deze minimaal twee jaar geduurd hebben. Ik deel de visie van Van Slooten in dit kader niet, die inhoudt dat de kans dat de werknemer een (transitie)vergoeding krijgt bij inwerkingtreding van een ontbindende voorwaarde onder de Wwz hoger zou zijn dan onder het oude recht. Er is mijns inziens geen basis voor een recht op een transitievergoeding.

Als de ontbindende voorwaarde onder de Wwz nog steeds mogelijk zou zijn, heeft de betrokken werknemer mijns inziens minder ontslagbescherming dan een werknemer met een tijdelijke arbeidsovereenkomst (immers: geen aanzegtermijn, geen transitievergoeding na twee jaar) en, zou ik menen, ook minder ontslagbescherming dan een werknemer die op staande voet ontslagen wordt. De toets of terecht is ontslagen wegens een dringende reden is met meer inhoudelijke waarborgen omkleed en de op staande voet ontslagen werknemer heeft, tenzij sprake is van ernstige verwijtbaarheid zoals bedoeld in artikel 7:673 lid 8 onderdeel c BW, wel recht op een transitievergoeding. Daarbij moet worden meegewogen dat de ontbindende voorwaarde volgens Boek 3 en Boek 6 BW kan zien op iedere toekomstige onzekere gebeurtenis en uit de rechtspraak van de Hoge Raad voor geldigheid van de ontbindende voorwaarde vooral randvoorwaarden volgen (zoals dat de werkgever de inwerkingtreding niet mag (kunnen) beinvloeden), maar weinig voorwaarden die de inhoud van de ontbindende voorwaarde inperken (behoudens geen strijd met een wettelijk opzegverbod). Een ontbindende voorwaarde kan dus ook zien op gebeurtenissen die inhoudelijk volstrekt geen dringende reden voor ontslag op staande voet op zouden leveren of überhaupt geen grond voor ('regulier') ontslag onder de Wwz. Van Slooten deelt deze visie ('Men kan dat niet baseren op de (veronderstelde) regel dat de als voorwaarde geformuleerde ontslaggrond ook door het UWV of de kantonrechter zou zijn aanvaard. Een dergelijke regel heeft de Hoge Raad namelijk niet gegeven.' $)^{6}$

\section{Lagere rechtspraak onder de Wwz}

Sinds de inwerkingtreding van de Wwz zijn mij drie zaken bekend waarin geoordeeld moest worden over de ontbindende voorwaarde. ${ }^{7}$ In een van deze zaken werd de ontbindende voorwaarde nietig geacht, namelijk toen de werkgever pas een beroep deed op het niet overleggen van een verklaring van goed gedrag nadat de werknemer zich ziek had gemeld. ${ }^{8}$ De rechtbank achtte het in strijd met goed werkgeverschap dat, ondanks dat eerder veelvuldig contact was geweest tussen werkgever en werknemer, de werkgever zonder enige voorafgaande waarschuwing (en na het verstrijken van de termijn waarbinnen de verklaring overgelegd moest worden) alsnog een beroep deed op de ontbindende voorwaarde. Daarmee kon volgens de rechtbank geconcludeerd worden dat de ontbindende voorwaarde mede afhankelijk was van het subjectieve oordeel van werkgever. Het opzegverbod tijdens ziekte speelde hierbij uiteraard ook een rol.

Bij de andere twee uitspraken zijn kanttekeningen te plaatsen, ook indachtig de hiervoor geschetste voorwaarden voortvloeiend uit rechtspraak van de Hoge Raad onder oud recht.

In de zaak die bij de Rechtbank Amsterdam ${ }^{9}$ speelde, zag de ontbindende voorwaarde op het stoppen van de musicalproductie en deed de werkgever een beroep op de ontbindende voorwaarde bij de acteurs omdat de productie verliesgevend bleek. De werkgever gaf eind mei 2016 aan dat de productie op 30 juni 2016 zou eindigen. De rechtbank vond met de werknemers dat de perkgever het besluit had genomen de productie te stoppen, maar billijkte de ontbindende voorwaarde toch omdat volgens de rechtbank vastgesteld kon worden dat iedere redelijk handelende werkgever geen andere keus had dan de productie te stoppen en dat het feit dat het formele besluit door de werkgever zelf was genomen dan geen belemmering vormde voor het inroepen van de ontbindende voorwaarde. Mij lijkt dat de toets of deze (bedrijfseconomische) omstandigheden tot voortijdige beëindiging mogen leiden onder de Wwz is voorbehouden aan het UWV en valt onder de toets van artikel 7:669 lid 3 onderdeel a BW en dat daarmee specifieke regels gelden zoals neergelegd in de Ontslagregels.

In de zaak die bij de Rechtbank Noord-Holland ${ }^{10}$ speelde, was de ontbindende voorwaarde gekoppeld aan het einde van een leerovereenkomst. Het ging om een leerling-monteur. Wat opviel was dat over de band van het wel of niet inhoudsloos worden van de arbeidsovereen-

7. Rb. Noord-Holland 19 april 2016, RAR 2016/125, Rb. Amsterdam 13 juli 2016, Prg. 2016/219 en Rb. Zeeland-West-Brabant 9 augustus 2016, ECLI:NL:RBZWB:2016:4944. Er kan overigens discussie zijn over de vraag of de Wwz directe werking heeft op een voorwaarde die voor de $W w z$ is overeengekomen.

8. Rb. Zeeland-West-Brabant 9 augustus 2016, ECLI:NL:RBZWB: 2016:4944

9. Rb. Amsterdam 13 juli 201, Prg. 2016/219.

10. Rb. Noord-Holland 19 april 2016, RAR 2016/125. 
komst een uitvoerige toets werd gedaan naar herplaatsingsmogelijkheden bij de werkgever voor ongediplomeerde monteurs. De werkgever betoogde dat die mogelijkheden er niet waren. De rechtbank achtte de ontbindende voorwaarde geldig. Mij lijkt dat, zoals hiervoor toegelicht, er in het kader van de toets of de ontbindende voorwaarde geldig is, geen ruimte is voor een extra toets op herplaatsingsmogelijkheden. Tevens oordeelde de rechtbank dat de werknemer geen beroep op vernietiging ex artikel 7:681 onderdeel a BW toekwam nu het een einde van rechtswege betrof. Dat de leerovereenkomst 8 oktober geëindigd was en de werkgever pas 30 november hiervan kennisnam en een beroep deed op de voorwaarde, maakte dit volgens de rechtbank niet anders. De arbeidsovereenkomst eindigde per 30 november 2015 van rechtswege, aldus de rechtbank. In feite was de einddatum van de arbeidsovereenkomst hier arbitrair.

Er zijn aldus de nodige kanttekeningen te plaatsen bij deze uitspraken, maar wat mij het meest opvalt is dat geen van deze lagere rechters (expliciet) gemotiveerd heeft of de ontbindende voorwaarde überhaupt nog verenigbaar is met het sinds 1 juli 2015 geldende Wwz-ontslagstelsel. Alhoewel het aantal gewezen uitspraken minimaal is, lijkt het erop dat wordt doorgevaren op de koers onder oud recht. Weliswaar is met de Wwz de gelaagde structuur van het Burgerlijk Wetboek niet gewijzigd, maar het stelsel is per 1 juli 2015 wel ingrijpend gewijzigd. Is de ontbindende voorwaarde nog verenigbaar met dat nieuwe stelsel?

\section{Argumenten voor en tegen handhaving ontbindende voorwaarde onder de Wwz}

Van Slooten geeft in zijn artikel twee redenen voor handhaving van de ontbindende voorwaarde onder de Wwz, die samengevat als volgt luiden:

1. Het algemeen vermogensrecht staat de ontbindende voorwaarde toe; uitgangspunt is samenloop, tenzij een bepaalde regel zich daartegen verzet. Van Slooten motiveert dit door dezelfde a-contrario-redenering toe te passen als de Hoge Raad in het Mungra-arrest onder oud recht heeft gedaan, te weten: artikel 7:667 lid 7 en 8 BW verbieden bepaalde ontbindende voorwaarden (wegens huwelijk, zwangerschap of bevalling) expliciet, dus de rest mag of is niet per se in strijd met het (nieuwe) ontslagrecht;

2. In de praktijk is geen groot gat geslagen in de ontslagbescherming. Slechts een aantal typen voorwaarden wordt toegestaan (waarbij volgens Van Slooten het niet langer beschikken over de vereiste papieren de meest voorkomende is). Er is niets dat volgens Van Slooten naar de letter een ontbindende voorwaarde zou verbieden:

- de regels onder de Wwz zien op opzegging en niet op andere beëindigingswijzen;
- dat geldt ook voor de herplaatsingsverplichting (die er volgens hem in zekere mate ook onder oud recht was);

- er is een grotere kans op een transitievergoeding als de arbeidsovereenkomst niet wordt voortgezet op initiatief van de werkgever (hiervoor heb ik al toegelicht dat ik die hogere kans niet zie gelet op de tekst van artikel 7:673 BW en de parlementaire toelichting op de Wwz-wijzigingen op dit punt);

- de meeste ontbindende voorwaarden vallen onder een Wwz-grond (met name de h-grond).

Deze - mijns inziens nogal tekstuele - benadering overtuigt mij niet.

In de eerste plaats is de vraag of de wetgever bij de inwerkingtreding van de $\mathrm{Wwz}$ aandacht heeft besteed aan handhaving van artikel 7:667 lid 7 en $8 \mathrm{BW}$. Er is geen enkel aanknopingspunt in de parlementaire geschiedenis daarvoor, laat staan dat hiermee een bewuste keuze is gemaakt de mogelijkheid van het aangaan van een arbeidsovereenkomst onder een ontbindende voorwaarde te handhaven. Aannemelijker is dat de bewuste artikelen simpelweg zijn blijven staan (en/of over het hoofd zijn gezien).

Veel belangrijker is mijns inziens dat materieel het ontslagstelsel met de Wwz ingrijpend is gewijzigd. Er is door de wetgever uitdrukkelijk gekozen voor een limitatief grondenstelsel, een verplichte route via UWV of kantonrechter, uitsluiting buitengerechtelijke vernietiging door de werknemer, beperktere mogelijkheden voor tijdelijke contracten en een expliciete(re) herplaatsingsverplichting. De ruimte die artikel 7:686 BW geeft (ontbinding via de rechter wegens niet-nakoming van de overeenkomst) is daarnaast (zeer) beperkt.

Ik ben van mening dat er aldus sterke argumenten zijn te concluderen dat dit gewijzigde Wwz-ontslagstelsel als exclusief door de wetgever is bedoeld. Op grond van de schakelbepalingen van de artikelen 3:59 en 6:216 BW zijn de vermogensrechtelijke bepalingen over de ontbindende voorwaarde niet van toepassing als sprake is van exclusieve regels en/of de aard van de rechtshandeling of rechtsbetrekking zich daartegen verzet.

De Hoge Raad heeft bovendien onder oud recht bij herhaling grote waarde gehecht aan het (geldende) ontslagstelsel en oordeelde onder oud recht reeds dat de ontbindende voorwaarde vanwege dit ontslagstelsel slechts bij uitzondering kon worden aanvaard. Dat zag dus op het ontslagstelsel geldend tot 1 juli 2015. Belangrijk is daarbij in ogenschouw te nemen dat dat een stelsel van open gronden was. De wijzigingen per 1 juli 2015 hebben het stelsel substantieel meer gesloten gemaakt. Mijn verwachting is dat de Hoge Raad dat ingrijpend gewijzigde ontslagstelsel van de Wwz zwaar zal laten wegen bij de vraag of een ontbindende voorwaarde nog verenigbaar is met dit nieuwe stelsel.

Daarnaast heeft de Hoge Raad onder oud recht geoordeeld dat een ontbindende voorwaarde geen wettelijk opzegverbod mag omzeilen. Verdedigbaar is mijns inziens ook dat - als geen sprake is van een van de limitatief opgesomde ontslaggronden in artikel 7:669 lid 3 BW - gelet op de strekking en de kenbare bedoeling van 
de wetgever bij de Wwz, een algemeen opzegverbod geldt. Een ontbindende voorwaarde wegens een niet in de wet opgesomde ontslaggrond zou dan dit algemene opzegverbod omzeilen en daarmee nietig zijn.

Ook De Laat vindt het moeilijk voorstelbaar dat de structurele wijzigingen in het ontslagrecht geen enkele invloed zullen hebben op rechtspraak inzake de ontbindende voorwaarde. ${ }^{11}$ Kenmerkend is, ook volgens De Laat, dat de Hoge Raad steeds de bescherming van het stelsel vooropstelt en dat de bescherming onder de Wwz alleen maar is toegenomen. Daarom zou de Hoge Raad volgens De Laat wel eens op zijn schreden terug kunnen moeten komen vanwege de uitgangspunten van het nieuwe wettelijke stelsel van ontslagrecht.

Ten tweede heeft Van Slooten aangevoerd dat de ontbindende voorwaarde geen groot gat heeft geslagen in het ontslagrechtstelsel. Ik vraag mij af of de werknemers in de hiervoor besproken lagere uitspraken dat ook zo ervaren hebben (zo betoogden de acteurs in de zaak bij de Amsterdamse Rechtbank van 13 juli 2016 dat zij beter af waren geweest als de werkgever faillissement had aangevraagd, omdat zij dan nog een opzegtermijn van zes weken hadden gekregen en doorbetaling van loon onder de garantieregeling van het UWV). Daarnaast doet de (goede) uitwerking in de praktijk, voor zover al meetbaar, niets af aan de dogmatische vraag of de ontbindende voorwaarde nog verenigbaar is met het Wwz-ontslagstelsel.

Van Slooten beargumenteert de handhaving van de ontbindende voorwaarde onder de Wwz vooral door naar de letter van de wet te wijzen. Zo gelden het grondenstelsel en de herplaatsingsverplichting alleen voor opzegging en ontbinding en niet voor een andere beëindigingswijze zoals de ontbindende voorwaarde. Deze letterlijke interpretatie doet mijns inziens geen recht aan de materiële toets die volgens de schakelbepalingen uit Boek 3 en Boek 6 BW uitgevoerd moet worden, te weten of de Wwz-ontslagregels door de wetgever exclusief bedoeld zijn (en de strekking van die regels) en zich verzetten tegen toepassing van algemene vermogensrechtelijke regels. Volgens mij kan moeilijk ontkend worden dat de wetgever met de $\mathrm{Wwz}$ bedoeld heeft ontslag goedkoper te maken (via de relatief lage transitievergoeding), maar dat ontslag uitsluitend toe te staan als het 'eerlijk' zou zijn, waarvoor limitatieve ontslaggronden en een herplaatsingsverplichting in de wet zijn opgenomen. Daar past de ontbindende voorwaarde niet bij.

Daarnaast betoogt Van Slooten dat de herplaatsingsverplichting onder oud recht ook al bestond, wat uiteraard juist is, maar mijns inziens in minder sterke mate dan onder de Wwz. Of de werknemer een - naar huidig recht - vergelijkbare herplaatsingsverplichting kan afdwingen in het geval van een ontbindende voorwaarde, betwijfel ik zeer. Als de ontbindende voorwaarde geldig wordt geacht, leidt inwerkingtreding tot een einde van rechtswege. Een beroep op de derogerende werk- ing van de redelijkheid en billijkheid is voorbehouden aan uitzonderlijke gevallen.

Tot slot wijst Van Slooten erop dat de meeste ontbindende voorwaarden die in de rechtspraak zijn toegestaan makkelijk onder een van de ontslaggronden uit artikel 7:669 lid 3 BW zullen vallen, bijvoorbeeld de h-grond. Dat is voor mij nu juist ook een reden de ontbindende voorwaarde niet langer aanvaardbaar te achten op dezelfde wijze als voor 1 juli 2015. De Wwz-ontslagregels kennen de werkgever immers een expliciete mogelijkheid toe om tot beëindiging van de arbeidsovereenkomst op die grond te komen. Een mogelijkheid die zowel materiële als procesrechtelijke waarborgen kent die de wetgever bij de Wwz welbewust gekozen heeft. $\mathrm{Zo}$ is het (onder omstandigheden) toegestaan bij bijvoorbeeld het ontbreken van de juiste papieren een beroep te doen op de h-grond, maar wél met een inhoudelijke toets door de kantonrechter (en/of appelrechter) en de nodige waarborgen, zowel op inhoud, proces als uitkomst (denk aan inachtneming van een bepaalde opzegtermijn en het recht op een transitievergoeding). Dat heet ontslagbescherming en juist die bescherming, die waarborgen, ontbeert een werknemer volledig als een ontbindende voorwaarde in werking treedt.

\section{Conclusie}

Van Slooten erkent dat het huis van het ontslagrecht, zoals hij dat beeldend omschrijft, aanzienlijk verbouwd is en dat dat kan betekenen dat 'op sommige meubels in dat huis een ander licht valt, hoewel niemand ze heeft aangeraakt'. Het lijkt erop dat lagere rechters onder de Wwz de oude meubels gewoon zijn blijven gebruiken, zonder het grote licht in het huis aan te doen. Zouden zij het grote licht aandoen, dan zou zichtbaar worden dat het huis dusdanig ingrijpend verbouwd is dat bepaalde meubels - zoals de ontbindende voorwaarde niet langer in dat verbouwde huis passen en bij het grofvuil gezet moeten worden. Alhoewel zo'n verbouwing ingrijpend en tijdsintensief is gebleken, is het grote voordeel dat de bewoners genoodzaakt worden weer eens kritisch naar die oude meubels te kijken. Zijn die nog wel passend en nuttig na de verbouwing? Het zou mij niet verbazen als geconcludeerd wordt dat deze verbouwing genoeg goede, nieuwe meubels heeft opgeleverd om te gebruiken voor hetzelfde doel. 